\title{
A Statistical Investigation of the Earthquake Predictions Using LURR
}

Keyin Peng, ${ }^{1}$ Xiangchu Yin, ${ }^{1,2,3}$ and Lang-Ping Zhang ${ }^{2}$

\begin{abstract}
In terms of the spatial scanning of LURR (Load-Unload Response Ratio), we have been predicting the seismic tendency within the next year for the mainland of China from 1995 to 2003. In order to make the quantitative retrospective assessment of LURR method, we compare the results with Poisson null hypothesis. The results show that the prediction by LURR method is much better than Poisson hypothesis.
\end{abstract}

Key words: Load-Unload Response Ratio (LURR), earthquake prediction, statistical assessment.

\section{Introduction}

The LURR (Load-Unload Response Ratio) method is an intermediate-term earthquake prediction approach. It was first proposed by YIN (1987) about twenty years ago and since then has undergone many improvements (YIN et al., 1991, 1995, 1996, 2000, 2004). The basic idea of LURR is: when the seismogenic system is in a stable state, its response to loading is nearly the same as its response to unloading, whereas when the system is approaching the unstable state, the response to loading is more sensitive than that to unloading. When a seismogenic system is in a stable or linear state the LURR value equals unity, whereas when the system lies outside of the linear state the LURR value will be larger than unity. The tide provides the loading and unloading in the current implementation.

During the first ten years, the retrospective inspections were performed by YIN et al. (1995) with hundreds of earthquake cases to validate the LURR method. For more than $80 \%$ of cases the LURR value (denoted by Y) fluctuates around 1 during the early stage of the seismogenic process and rises along with the approaching occurrence of a strong earthquake. Then the $Y$ values decrease after they reach their

\footnotetext{
${ }^{1}$ China Earthquake Networks Center, CEA (China Earthquake Administration), Beijing 100036, China. E-mail: pengkeyin@seis.ac.cn

${ }^{2}$ LNM (Laboratory for Non-linear Mechanics), Institute of Mechanics, CAS, Beijing 100080, China. E-mail: yin@LNM.imech.ac.cn; zhanglp@LNM.imech.ac.cn

${ }^{3}$ CSB, Institute of Geophysics, Beijing 100084. E-mail: xcyin@public.bta.net.cn
} 
maximum (significantly larger than 1). In contrast, for seven "stable" regions with low seismicity (no earthquake with $M \geq 4$ occurred in the examined period) on the Chinese mainland, the $Y$ value always fluctuates slightly around 1 during the entire duration without any significant deviations (YIN et al., 1995). These results suggest that LURR is available to be a precursor of strong earthquakes.

The Lattice Solid Model (MorA et al., 2002; WANG et al., 1998-2000, 2004), FEM model and chains network model (LiANG et al., 1996) were used to simulate the evolution of damage and failure of heterogeneous brittle solid and in the meantime to measure the variation of LURR prior to the macro-fracture similar to the strong natural earthquake. The simulating results show that LURR values become high along with the increasing load and reach their peak point, then drop rapidly prior to the main event.

There also have been numerous laboratory studies on LURR (SHI et al., 1994; YIN et al., 2004). XING-jUE SHI et al. (1994) conducted laboratory studies on variations of LURR during rock failure in the early 1990s. The result is similar to the theory expectation, that is, $Y$ is close to 1 when the stress is small, increases when beyond the elastic phase, and grows remarkably just before fracture.

Although LURR theory is easily accepted theoretically and has been proved valid by laboratory modeling, numerical simulation and case inspections as well, it must be tested ultimately in real earthquake practices. YIN et al. (2000) applied LURR to real earthquake prediction practice in the period of 1993-1998. Among the 18 total predicted cases, 12 cases were correct, 6 cases false. The successful cases included the 1994 Northridge, USA earthquake and the 1995 Kanto, Japan earthquake (YIN et al., 1996).

\section{Earthquake Prediction in Terms of LURR}

After retrospective study with hundreds of earthquake cases and some tentative practice of earthquake predictions in selected regions, we attempted to predict the seismic tendency of China from 1995. We used the catalogue provided by the network of China. For each quake we calculated its increment of Coulomb Failure Stress caused by tides, to judge loading or unloading, and then performed spatial scanning of LURR with the formula:

$$
Y=\frac{\left(\sum_{i=1}^{N^{+}} E_{i}^{m}\right)_{+}}{\left(\sum_{i=1}^{N^{-}} E_{i}^{m}\right)_{-}}
$$

where $E$ denotes seismic energy which can be calculated according to the GutenbergRichter formula (KANAMORI and ANDERSON, 1975), the sign " + " means loading and "-" unloading, $m=1 / 2$ (thus $E^{m}$ denotes the Benioff strain). 
Since the preparation and occurrence process of earthquakes are controlled not only by deterministic dynamical law but also affected by stochastic or disorder factors, ZHUANG and YIN (1999) studied the influence of random factors on LURR in order to estimate the threshold above which $Y$ value can be regarded as an earthquake precursor within a specified confidence level. They gave the critical value of LURR $Y_{\mathrm{c}}$ that depends on the number of earthquakes under different specified confidence levels. The greater the earthquake number is, the lower the $Y_{\mathrm{c}}$ (critical value of LURR). The earthquake number is usually different. Consequently we use the ratio $Y / Y_{\mathrm{c}}$ instead of $Y$ where $Y_{\mathrm{c}}$ is the threshold at a confidence level of $95 \%$.

In the end of every year we obtained a distribution map which shows the anomalous LURR regions in the Chinese mainland from 1995. According to the maps we predicted that earthquakes with magnitude $\geqq 5$ would occur in the anomalous LURR regions in the next year.

From 1995 to 2003 we have been predicting the seismic tendency within the next year for the mainland of China, according to the spatial scanning of LURR. The results were issued in the books pertaining to the research on the seismic tendency of China between 1996-2004 (YIN et al., 1995-2003). Now it is time to evaluate the prediction effect of LURR.

\section{Statistical Tests}

How to evaluate the prediction effect is a controversial topic. In China the $R$ score method has been the most popular one. An $R$ score is approximately 0 for completely random guesses, and approximately 1 for completely successful predictions. SHI et al. (2001) evaluated the annual earthquake predictions of the China Seismological Bureau (CSB) by means of an $R$ score. They concluded "the average $R$ score of the annual predictions in China in the period 1990-1998 is about 0.184, and concluded that earthquake prediction in China is still in a very preliminary stage, barely above a pure chance level" and YAOLIN et al. (2001) believed also that it is fact to use a single index to cover all important aspects in evaluating earthquake predictions. Previous tests of earthquake forecasts in the USA have emphasized the likelihood test (KAGAN and JACKSON, 2000; Rundle et al., 2002; Holliday et al., 2005). "These tests have the significant disadvantage that they are overly sensitive to the least probable events" (Holliday et al., 2005). In the present paper we adopt a method suggested originally by D. Jackson.

We used the catalogues published by the China Seismograph Network (CSN) in our test. Using a strict interpretation, only earthquakes with magnitude $\mathrm{M} \geq 5.0$ would be counted.

The $Y$ value contour maps were subdivided into spaces by $0.5^{\circ} \times 0.5^{\circ}$. For each anomaly LURR region, called 'dangerous' region, we count the number of earthquakes of $\mathrm{M} \geq 5.0$ which occurred in the next year and acquire Poisson 
earthquake probability directly from the data file of probability density of earthquakes for $\mathrm{M} \geq 5.0$, provided by Kagan who used Poisson null hypothesis which calculated the probability density of earthquakes worldwide based on Harvard CMT data catalogues. The probabilities mean the rates of earthquakes occurred intermediately in the predicted regions every year.

According to the data of CSN more than 20 earthquakes with magnitude $\mathrm{M} \geq 5$ occurred generally on the chinese mainland every year. A part of such events occurred in regions where the scarce data are unavailable for LURR calculation. Therefore the earthquakes which occurred in the data scarcity regions were ignored in this paper.

Tabulate the number of earthquakes of $\mathrm{M} \geq 5.0$ which occurred in the next year and the accumulative Poisson earthquake probability for each prediction region (Table 1 is an example in 1997), and plot the accumulated earthquake number against cumulative Poisson earthquake probability.

Figure 1 is the test results of the forecasts according to LURR spatial scanning from 1995 to 2003. The figure in the box in Figure 1 is the year when the prediction was made for the next year. For example, "2003" means the prediction for seismic tendency in 2004 made at the end of 2003. If the actual earthquake strictly obeys Poisson hypothesis it is a bisector line in the figure (see the red lines in Fig. 1). If the predictions are better than the Poisson hypothesis, the accumulated earthquake

Table 1

Statistics of EQ prediction using LURR and Poisson hypothesis in the example of Year 1997

\begin{tabular}{ccccc}
\hline Region No. & Probability & $\Sigma$ Probability & Earthquake & $\Sigma$ Earthquake \\
\hline 1 & 0.8649 & 0.8649 & 1 & 1 \\
2 & 0.0454 & 0.9103 & 0 & 1 \\
3 & 0.5351 & 1.4454 & 1 & 2 \\
4 & 0.2087 & 1.6541 & 1 & 3 \\
5 & 0.6365 & 2.2906 & 0 & 3 \\
6 & 0.0552 & 2.3458 & 0 & 4 \\
7 & 0.1281 & 2.4739 & 1 & 6 \\
8 & 1.0618 & 3.0618 & 2 & 6 \\
9 & 0.0884 & 3.6241 & 0 & 6 \\
10 & 0.0288 & 3.6529 & 0 & 6 \\
11 & 0.036 & 3.6889 & 0 & 9 \\
12 & 0.2938 & 3.9827 & 3 & 10 \\
13 & 0.5278 & 4.5105 & 0 & 10 \\
14 & 0.1278 & 4.6383 & 1 & 10 \\
15 & 0.0096 & 4.6479 & 0 & 11 \\
16 & 0.1387 & 4.7866 & 0 & 11 \\
17 & 0.0487 & 4.8353 & 0 & 12 \\
18 & 0.2238 & 5.0591 & 1 & 13 \\
19 & 0.0094 & 5.0685 & 0 & \\
20 & 0.4657 & 5.5342 & 1 & 1 \\
21 & 0.6621 & 6.1963 & & \\
\hline
\end{tabular}



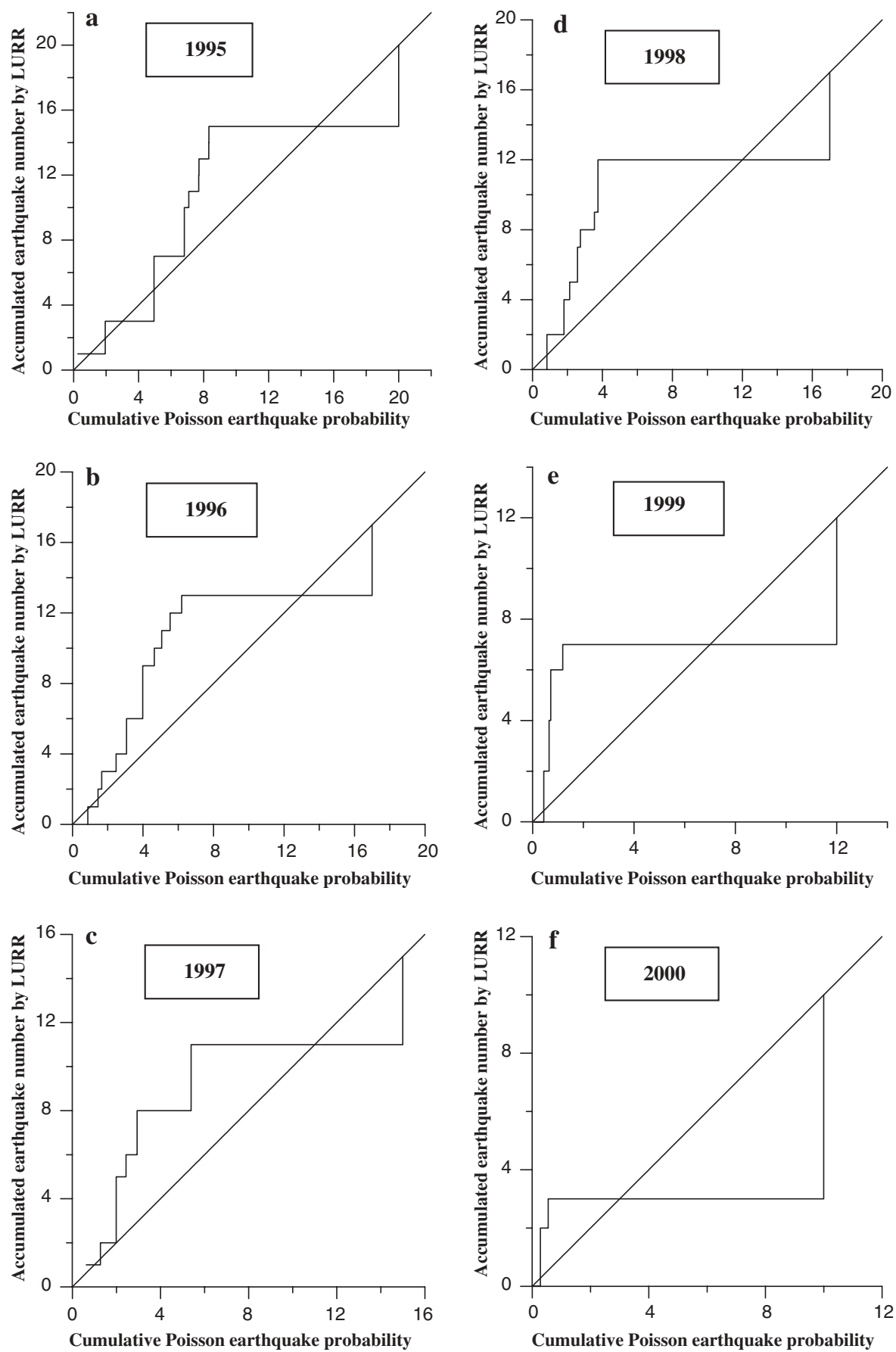

Figure 1

Accumulated earthquake number predicted by LURR vs. cumulative Poisson earthquake probability from 1995 to 2003 on the Chinese mainland. 

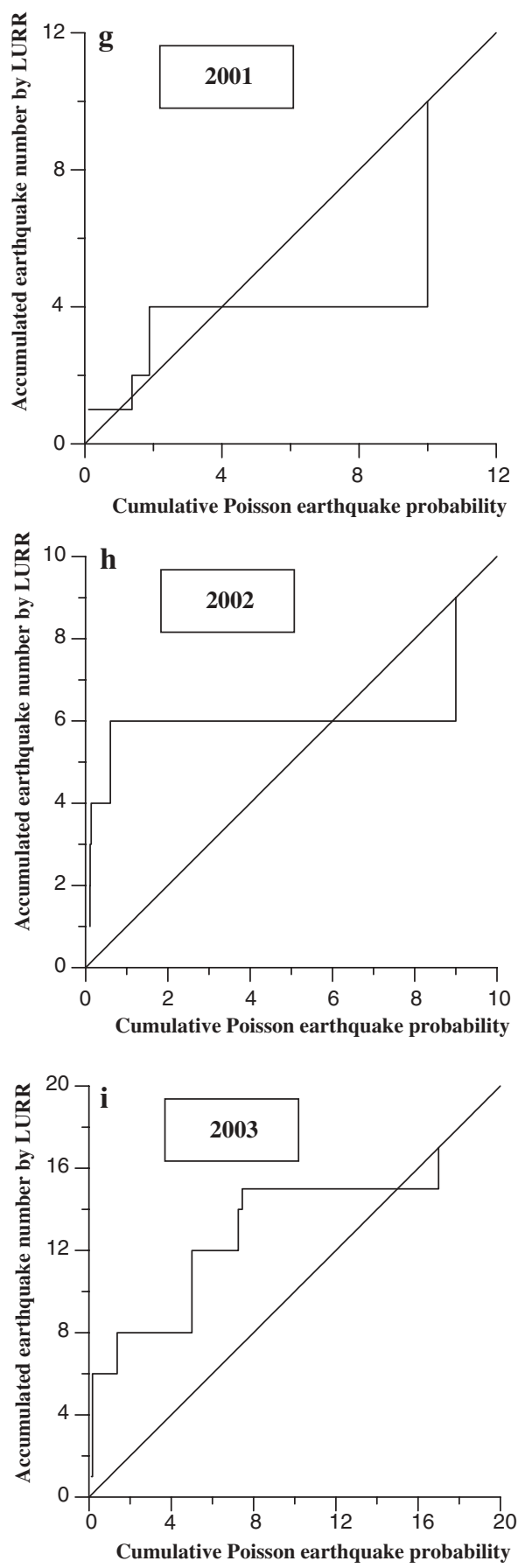

Figure 1

(contd.) 
numbers will be greater than the cumulative Poisson earthquake probability and the curves will be above the bisector lines.

It is true that some regions predicted by LURR are worse than Poisson hypothesis (see the 2nd, 5th, 10th and 19th regions in Table 1), however those predicted successfully (see the 1st, 4th, 7th and 14th regions in Table 1) outperform Poisson hypothesis to such a degree that the overall effect still shows the better performance of the LURR method (see the left part to the diagonal of the plots). Regarding the missing cases (strong EQ occurred without prediction, corresponding to the vertical line right to the diagonal of the plots), a majority of results shows that the number of predicted cases is obviously greater than the number of missing cases except in 2000 and 2001.

\section{Critical Region}

Usually the scan radius we used is 100 to $150 \mathrm{~km}$. However, before the Kunlun Earthquake (M 8.1, Nov. 14, 2001) we did not find an anomaly in the LURR contour map near the epicenter. Further study shows that anomalous high value LURR appears prior to the Kunlun main shock while the radii are from 400 to $1100 \mathrm{~km}$.

When we calculate the values of $Y$ for a region and specified time window, the $Y$ values are a function of the size of the region. The size which maximizes the peak value of LURR is called critical region size. In Figure 2 the curve is plotted for LURR against the radius $R$ of the region for Kunlun earthquake. The critical region size for Kunlun earthquake is $R=800 \mathrm{~km}$.

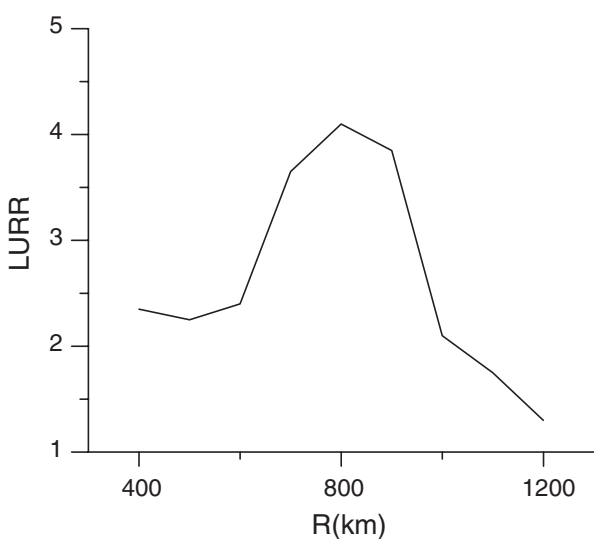

Figure 2

The peak values of LURR against the radius $R$ of the region for Kunlun earthquake. 
Fourteen earthquakes that occurred in China have been studied with magnitudes ranging from 5.1 to 8.1 . It is found that the critical region size scales with the magnitude of earthquake (Fig. 3).

Fitting the data in Figure 3, the function between critical region size and the magnitude is

$$
\log R(\mathrm{~km})=0.087+0.34 \mathrm{M} .
$$

JAUME and SYKeS (1999) have found that the critical regional size for accelerating energy release (AER/AMR) is

$$
\log R \propto 0.36 \mathrm{M}
$$

and BowmAn et al. (1998) found

$$
\log R \propto 0.44 \mathrm{M} .
$$

Obviously they agree with each other quite well.

In our previous work (YIN et al., 2002), we have discovered that a strong correlation is evident between the AMR/AER and LURR critical regional sizes that suggest these two observations maybe have a common physical mechanism. Furthermore, based on the results presented in Figure 3, the critical region sizemagnitude scaling relation for LURR provides a means to estimate the magnitude of an upcoming earthquake.

\section{Discussion and Conclusion}

The statistical results show that the prediction by LURR method is considerably better than the Poisson hypothesis. Considering the complexity of the earthquake,

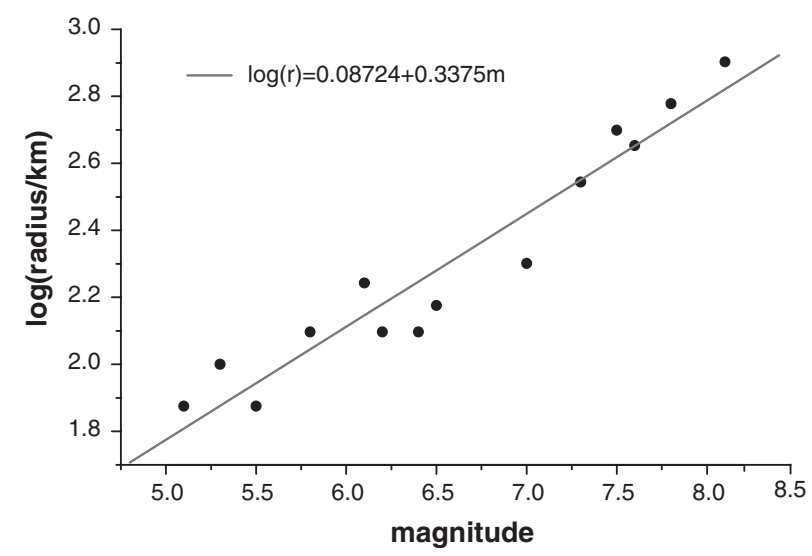

Figure 3

Critical region radius $r$ as a function of the magnitude of 14 earthquakes which occurred in China. 
some factors, such as critical size, should be considered. As discussed above, to predict earthquakes with different magnitude, we should select different radii.

It is exhilarating that the prediction results using LURR have been increasingly better. Especially in 2003 (see the last plot in Fig. 1), for the total of 16 earthquakes with magnitude M 5 or larger which occurred in regions in which the observed data are good enough to calculate LURR in 2004, the number of predicted cases is 15 , whereas the number of missing cases is only 1 .

\section{Acknowledgements}

This research is supported by the Natural Science Foundation of China (Grant Nos. 10232050, 10572140, and 2005CB724800), the key project of the ninth five-year plan of MOST (2004CB418406, 2002CB412706) and CEA (10604). We are grateful to Professors Davi Jackson, Zhengkang Shen for their highly-valued suggestions and Professor Y. Kagan for his Poisson earthquake probability data files for $M \geq 5.0$ based on PDE (1968-1995) data catalogues.

\section{REFERENCES}

Bowman, D.D., Oulllon, G., Sammis, C.G., Sornette, A., and Sornette, D. (1998), An observational test of the critical earthquake concept, J. Geophys. Res. 103, 359-372.

Holliday, J.R., Rundle, J. B., Tiampo, K. F., Klein, W., and Donnellan, A. (2005), Systematic procedural and sensitivity analysis of the pattern informatics method for forecasting large ( $\mathrm{M} \geq 5)$ earthquake events in southern California, Pure Appl. Geophys., in press (2005).

Jaume, S.C. and SyKeS, L.R. (1999), Evolving towards a critical point: A review of accelerating seismic moment/energy release prior to large and great earthquakes, Pure Appl. Geophys. 155, 279-306.

KaGAN, Y. Y. and JACKSON, D. D. (1995), New seismic gap hypothesis: Five year's after, J. Geophys. Res. 100(B3), 3943-3959.

KaGAN, Y. Y. and JACKsOn, D. D. (2000), Probabilistic forecasting of earthquakes, Geophys. J. Int. 143, 438-453.

Kanamori, H. and Anderson, D.L. (1975), Theoretical basis of some empirical relation in seismology, Bull. Seismol. Soc. Am. 65, 1073-1096.

Liang, N., LiU, Q., Li, J., and Song, H. (1996), A chains network model simulating meso-mechanics behavior and micro- damage evolution of in situ reinforced ceramics, Advanced in Engineering Plasticity and Its Applications (eds. ABe, T. and Tsuta, T.) (Pergamon, Amsterdan, 1996) pp. 141-146.

Mora, P., Wang, Y., Yin, C., Place, D., and Yin, X.C. (2002), Simulation of load-unload response ratio and critical sensitivity in the lattice solid model, Pure Appl. Geophys. 159, 2525-2536.

Rundle, J. B., Tiampo, K. F., Klein, W., and Martins, J. S. S., Sel-forganization in leaky threshold systems: The influence of near mean field dynamics and its implications for earthquakes, neurobiology, and forecasting, Proc. Natl. Acad. Sci. USA 99, 2514-2521, Suppl. 1 (2002).

ShI, X., Xu, H., WAN, Y., Lu, Z., and CHEN, X. (1994), The rock fracture under simulated tide force-Laboratory study on the loading and unloading response ratio (LURR) theory, Acta Geophysica Sinica 37, 631-636.

Shi, Y. L., LiU, J., and Zhang, G. M. (2001), An evaluation of Chinese annual earthquake predictions, 1990-1998, J. Appl. Prob. 38a, 222-231. 
WANG, Y.C., YIN, X.C., and WANG, H.T. (1998), The simulation of rock experiment on load/unload response for earthquake prediction, Earthq. Res. China 14(2), 126-130.

WANG, Y.C., YIN, X.C., and WANG, H.T. (1999), Numerical simulation on load/unload response ratio (LURR) theory, Chinese J. Geophys. 42(4), 527-536.

WANG, Y.C., YIn, X.C., KE, F.J., XIA, M.F., and PENG, K.Y. (2000), Simulation of rock failure and earthquake process on mesoscopic scale, Pure Appl. Geophys. 157, 1905-1928.

Wang Y.C., Mora, P., Yin, C., and Place, D. (2004), Statistical tests of load-unload response ratio signals by lattice solid model: Implication to tidal triggering and earthquake prediction, Pure Appl. Geophys. 12, 1829-1839.

YIN, X.C. (1987), A new approach to earthquake prediction, Earthq. Res. China 3, 1-7 (in Chinese with English abstract).

YIN X.C. and YIN, C. (1991) The precursor of instability for nonlinear systems and its application to earthquake prediction, Science in China, 34, 977-986.

YIn, X.C., Chen, X.Z., Song, Z.P., and YIN, C. (1995), A new approach to earthquake prediction: The load/ unload response ratio (LURR) theory, Pure Appl. Geophys. 145, 701-715.

YIN, X.C., Song, Z.P., and WANG, Y.C. (1996), Temporal variation of LURR in kanto and other regions in Japan and its application to earthquake prediction, Earthq. Res. China 10, 381-385.

Yin, X.C., Wang, Y.C., PAng, K.Y., BaI, Y.L., Wang, H.T., and Yin, X.F. (2000), Development of a new approach to earthquake prediction - load/unload response ratio (LURR) theory, Pure Appl. Geophys. 157, 2365-2383.

Yin, X.C., Mora, P., Peng, K.Y., Wang, Y.C., and Weatherly, D. (2002), Load-unload response ratio and accelerating moment/energy release, critical region scaling and earthquake prediction, Pure Appl. Geophys. 159, 2511-2524.

YIN, X.C., Zhang, H.H., and YU, H.Z. (2004), Acoustic emission experiment of rock failure under cycling load, The 4th ACES Workshop, July 9-14, Beijing China (2004).

Yin, X.C., Zhang, H.H., Yu, H.Z., Zhang, Y.X., and PenG, K.Y. (2003), Prediction of seismic tendency of Chinese mainland in 2004 in terms of LURR, in book The Research on Seismic Tendency of China in 2004, (ed. by Center for Analysis and Prediction), CSB, pp. 282-285, (Seismological Press, Beijing, 2003) (in Chinese).

ZHUANG, J.C. and YIN, X.C. (1999), Random distribution of the load/unload response ratio (LURR) under assumptions of poisson model, Earthq. Res. China 15, 128-138.

(Received December 20, 2004, reveised September 12, 2005, accepted September 14, 2005)

(1) To access this journal online: http://www.birkhauser.ch 